\title{
ANÁLISIS DE UNA OPERACIÓN INDUSTRIAL DE SUMINISTRO DE COMBUSTIBLE DIÉSEL B5 Y DESARROLLO DE UNA SOLUCIÓN DE OPTIMIZACIÓN
}

\author{
Mauricio AzÁlgara Bedoya* \\ Universidad Internacional Iberoamericana, México
}

Recibido: 5 de diciembre del 2018 / Aprobado: 23 de enero del 2019

doi: 10.26439/ing.ind2019.n037.4542

RESUMEN: En el marco de la ejecución del megaproyecto minero Las Bambas, se tuvo regulada la operación industrial de suministro de combustible diésel B5 mediante el contrato CB02912 del que fueron partes Xstrata Copper y Petróleos del Perú. Se estimó en la operación industrial hasta un $8 \%$ de bienes no entregados entre los años 2012 y 2013 , desabastecimiento intempestivo de combustible en instalaciones del cliente e incumplimiento de la especificación del nivel de limpieza del combustible, entre otros incidentes. La presente investigación establece los lineamientos para una gestión integral de contrato.

Palabras clave: diésel / sistema de gestión / contrato / suministro de combustible

\section{ANALYSIS OF AN INDUSTRIAL OPERATION OF B5 DIESEL FUEL SUPPLY AND DEVELOPMENT OF AN OPTIMIZATION SOLUTION}

ABSTRACT: Within the framework of the Las Bambas mining megaproject, the industrial operation of B5 diesel fuel supply was regulated by contract CB02912, in which the parties involved were Xstrata Copper and Petróleos del Perú. In the industrial operation, it was estimated that up to $8 \%$ of goods were not delivered between years 2012 and 2013, resulting in untimely fuel shortages in the customer's facilities, noncompliance with diesel fuel cleanliness standards, among others. The present research establishes the guidelines for the comprehensive management of the contract.

Keywords: diesel / management system / contract / fuel supply

\footnotetext{
*mazalgarab@gmail.com
} 


\section{INTRODUCCIÓN}

El megaproyecto minero Las Bambas inicia la fase de construcción en el 2012. Previamente, en el 2011, con la finalidad de afrontar esta fase última, Xstrata Copper inicia la licitación LD00611 para el suministro de combustible para la Operación Tintaya y los Proyectos Mineros de Antapaccay y Las Bambas. De este modo se suscribe el contrato de suministro de combustible CB02912 entre Xstrata Las Bambas, S. A. y Petróleos del Perú, S. A. (Petroperú) con la finalidad de abastecer de diésel B5, un destilado medio con $5 \%$ de biodiésel B100, conocido también como Diésel Ultra (Petroperú, 2011), a diversos puntos de recepción en el proyecto minero durante un periodo de cinco años. Adicionalmente, se suscribe el contrato directo OFP10351 entre Petroperú y Servosa Cargo S. A. C., en el que se terceriza el transporte del bien, entre otros aspectos, como parte de la solución logística integral para el suministro del bien.

Contando la operación industrial de suministro de combustible con la suficiente complejidad para llevar a cabo una investigación es que esta se desarrolla, con la finalidad de analizar y proponer lineamientos para el desarrollo de una solución de optimización para la gestión integral de contrato y de cadena de suministro basada en la implementación de buenas prácticas para la dirección de proyectos del Project Management Institute (PMI), además de las series de normas ISO 9000, ISO 14000 y OHSAS 18000.

El presente artículo aborda únicamente los resultados de la investigación en fase integradora para enfocarse en el objetivo general de la investigación que es la elaboración de una solución ingenieril para la optimización de la operación industrial de referencia. Sin embargo, se abordan los aspectos metodológicos no solamente de la investigación en fase integradora sino también de las investigaciones en fase cualitativa y cuantitativa.

\section{PLANTEAMIENTO DE LA INVESTIGACIÓN}

\subsection{Justificación}

Mediante la investigación se proponen soluciones técnicas y económicas capaces de optimizar el uso de recursos económico-financieros, materiales y técnicos o tecnológicos para lograr el objeto del contrato CB02912 y otros contratos similares. La aplicación de la metodología resultante de la presente investigación pretende ser de utilidad a la empresa estatal Petroperú y a las empresas pertenecientes al sector de la gran minería en lo que se refiere al desarrollo de los procesos de comercialización de combustible diésel B5, particularmente en materia de cumplimentación contractual. 


\subsection{Problema de investigación}

\subsubsection{Contexto}

De julio del 2012 a setiembre del 2013 se presentó un conflicto en el marco de una de las operaciones comerciales de diésel B5 para uso industrial de Petroperú (Petroperú, 2014), regulada por medio del contrato de suministro de combustible CB02912 entre Petroperú y Xstrata, la empresa que desarrolló el megaproyecto minero Las Bambas, considerado una de las inversiones mineras más importantes de la primera década del siglo XXI y que, adicionalmente, consolidaría al Perú como el segundo productor de cobre en América Latina (Proinversión, 2005).

El contrato de suministro de combustible CB02912 consideraba en su ejecución la tercerización del transporte de combustible por medio del contrato de servicio de transporte de combustible celebrado entre Petroperú y Servosa Cargo. Esta última parte se consideraba no solamente un transportista (operador logístico 2PL) sino también un operador logístico del tipo 3PL. En este sentido, Petroperú contrataba a Servosa Cargo como empresa especialista en actividades logísticas relativas al suministro de diésel B5. El vínculo entre Petroperú y Servosa Cargo se encontraba regulado por el contrato OFP103541, suscrito en el 2012.

\subsubsection{Conflicto}

En el periodo de referencia se observó el desabastecimiento intempestivo de diésel B5 en las instalaciones del proyecto minero. Además, Petroperú incumplió la especificación respecto del nivel de limpieza del suministro a Xstrata ocasionando daños y perjuicios, lo cual se tradujo en su incursión en riesgo de penalización. Cabe mencionar que si bien el responsable directo del desabastecimiento frente a Xstrata fue Petroperú, dado su vínculo contractual, en ocasiones el responsable inmediato era la empresa Servosa Cargo, la encargada del transporte del combustible.

\subsubsection{Problema identificado y delimitado}

Se estima un $8 \%$ de bienes no entregados dentro del plazo establecido en el contrato, y un cumplimiento de hoja de ruta por debajo del 95 \% (Azálgara, 2018). Lo anterior es producto de los siguientes aspectos: una gestión inadecuada del contrato de suministro, una programación inefectiva de suministro de combustible, la incursión en fallas mecánicas y un incremento del nivel de particulado por mantenimiento inefectivo.

El $8 \%$ de bienes no entregados representa aproximadamente 3952800 galones de diésel B5 que no necesariamente se dejaron de entregar, sino que se entregaron fuera de fecha. La cantidad mencionada proviene de una estimación hecha en base al 8 \% del 
total de suministro esperado de diésel B5, establecido en acuerdo mutuo de partes en la suscripción del contrato CB02912.

\section{Formulación del problema}

¿Cómo podría mejorarse el modelo de negocio del contrato CB02912 en cuanto al desempeño de su ejecución en materia de operatividad industrial, accidentabilidad y administración de impactos ambientales?

\section{Pregunta general de investigación}

¿Qué impidió la ejecución efectiva del contrato CB02912?

\section{Preguntas específicas de investigación}

- ¿Cómo se modelaría un sistema de gestión integral para la ejecución de contratos de suministro de combustible diésel B5 a compañías pertenecientes a la gran minería haciendo uso de estándares internacionales?

- ¿Desarrolló Petroperú los procesos de planificación, organización, dirección, ejecución y control para la atención del contrato CB02912?

- ¿Contó Petroperú con los recursos necesarios para la atención del contrato?

- ¿Cuáles fueron los incidentes de mayor riesgo (probabilidad y severidad) en la ejecución del contrato?

- ¿Fue efectivo el sistema de suministro de combustible?

- ¿Qué impactos ambientales del proyecto minero Las Bambas afectaron la ejecución del contrato?

- ¿Cuáles serían las especificaciones de un sistema de gestión integral del contrato?

\subsection{Objetivos}

\subsubsection{Objetivo general}

Elaborar una solución ingenieril que optimice la operación industrial de suministro de combustible diésel B5 al proyecto minero Las Bambas, basada en la adecuación integrada de estándares de gestión en materia de proyectos, calidad, ambiente y seguridad industrial. 
Objetivos específicos ${ }^{1}$

- Definir el problema del sistema de gestión original del contrato de suministro de combustible CB02912.

- Desarrollar un modelo para analizar los aspectos de confiabilidad del sistema de gestión original del contrato CB02912 que permita investigar, por un lado, la prevención de riesgos laborales y ambientales y, por otro lado, la respuesta rápida cuando surgen incidentes.

- Desarrollar una solución que optimice la operación industrial de suministro de combustible diésel B5 basada en la adecuación de la metodología PMI para la gestión de proyectos y de las series de normas ISO 9000, ISO 14000 y OHSAS 18000 sobre gestión ambiental y seguridad industrial, respectivamente, en los proyectos mineros en Perú.

\section{MARCO TEÓRICO CONCEPTUAL}

\subsection{Semblanza histórica}

La presente investigación parte del contexto de las condiciones de suministro de combustible para el proyecto minero Las Bambas, determinadas en la Licitación LD00611 en el 2011, y en la suscripción del contrato CB02912 en el 2012. Adicionalmente se suscribe el contrato directo OFP103541 por servicio de transporte en el 2012.

\subsection{Antecedentes}

La fase de construcción del proyecto minero Las Bambas se inició en el 2012, contando con cerca de 16500 trabajadores a fines del 2013 (Samardzich, 2014). En el 2013, la minera Xstrata y el trader de commodities más grande del mundo, Glencore, aprueban de mutuo acuerdo su fusión (Custodio, 2013). Estando valuado el proyecto minero Las Bambas en USD 5850000 000, fue adquirido por MMG Limited, filial de China Minmetals Corp., donde se procedió con un contrato de suministros a largo plazo por aproximadamente el 57,31 \% del concentrado de cobre a producirse en Las Bambas en el 2014 (Michelmore, 2014). La operación comercial inicia en el 2016, siendo MMG Limited la principal accionista y operadora del proyecto (Montoya, 2015).

1 La investigación considera tres objetivos específicos adicionales que no abordamos en el presente artículo por razones de síntesis. 


\subsection{Relaciones entre teorías y modelos que inspiran la investigación}

Las principales relaciones entre las teorías y modelos se presentan en el diagrama de la figura 1.

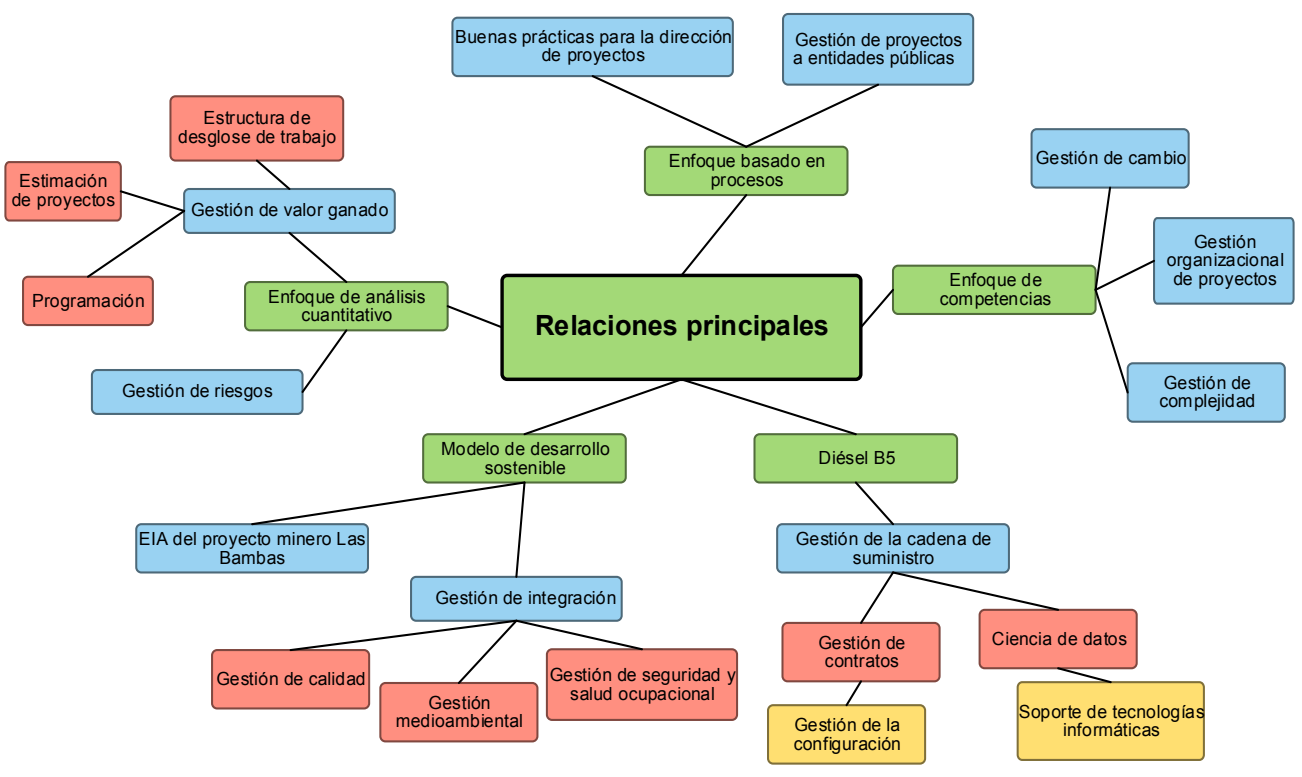

Figura 1. Relaciones principales entre teorías y modelos que inspiran la investigación

Nota: El presente diagrama es del tipo mind map, generado por medio del productor de diagramas de flujo en línea Lucidchart.

Elaboración propia

El enfoque basado en procesos inspira la investigación. La Organización Internacional de Normalización define este enfoque como "la aplicación y gestión de un sistema de procesos dentro de una organización, cuyos procesos se identifican e interactúan entre sí, para la obtención de resultados" (OIN, 2008, p. 6). Este enfoque incluye la aplicación de buenas prácticas para la dirección de proyectos bajo el enfoque del PMI para fines de la presente investigación; el PMI (2013) sostiene que la aplicación de buenas prácticas significa estar de acuerdo en que la aplicación de conocimientos, habilidades, herramientas y técnicas adecuados pueden aumentar las posibilidades de éxito de los proyectos.

Se aplica un enfoque de competencias, lo cual se traduce en el estándar del PMI conocido como "Marco para el desarrollo de competencias del director de proyectos". 
Este estándar estaría orientado no únicamente a los directores de proyecto sino a todas las personas con interés en la dirección de proyectos (PMI, 2007).

Adicionalmente se aplica un enfoque de análisis cuantitativo con la finalidad de abordar aspectos de gestión de riesgo y gestión de valor ganado. De acuerdo con Render, Stair y Hanna (2012), "el enfoque del análisis cuantitativo consiste en definir un problema, desarrollar un modelo, obtener los datos de entrada, desarrollar una solución, probar la solución, analizar los resultados e implementarlos" (p. 3).

Por otro lado, se pone particular énfasis en el diésel B5 en cuanto a la gestión de la cadena de suministro de este bien ya que, según Waters (2010), este tipo de gestión obliga a extender la lógica de la logística upstream a los proveedores y la downstream a los clientes finales.

La sostenibilidad es parte de los bloques de relaciones principales y se traduce en considerar los distintos eventos y objetos de la investigación como parte de un modelo de desarrollo sostenible que cuenta, como insumo de información, con el estudio de impacto ambiental del proyecto minero Las Bambas, donde figura la siguiente información: marco legal, descripción del proyecto, metodología para la evaluación de impactos ambientales y sociales entre otros. Según Golder Associates Perú, S. A. (2010), la información anterior tiene la finalidad de cumplir con la legislación peruana. El modelo de desarrollo sostenible se adecúa a la normatividad del Perú también en materia de comercialización de combustible diésel B5 que responde a regulaciones económicas y sociales (Osinergmin, 2015). La normatividad relativa a seguridad industrial minera es de relevancia ya que se permite implementar un sistema de gestión de seguridad (Ministerio de Energía y Minas, 2015), además de aquella que corresponde a la gestión ambiental, pues se propone una regulación acorde con el Reglamento de Protección Gestión Ambiental para las Actividades de Explotación, Beneficio, Labor General, Transporte y Almacenamiento (DS 0402014EM, 2014).

\section{ASPECTOS METODOLÓGICOS}

\subsection{Alcance de la investigación}

Para el estudio de la ejecución del contrato CB02912, es menester aplicar una metodología de la investigación con un enfoque mixto: por un lado cualitativo, debido a la recolección de datos no numéricos para descubrir o afinar preguntas de investigación en el proceso de interpretación (Hernández, Fernández y Baptista, 2006), y por otro lado cuantitativo, por la necesidad de recolectar datos cuantificables (medición numérica y análisis estadístico) para establecer patrones de comportamiento y probar hipótesis (Hernández, Fernández y Baptista, 2006). 


\subsection{Hipótesis principal}

Se conjetura la reducción de no conformidades en el suministro de combustible diésel B5 en el proyecto minero Las Bambas, a partir de la implementación de estándares de gestión de proyectos, calidad, ambiente y seguridad industrial en la gestión del contrato CB02912, logrando una mejora de proceso en el modelo de negocio, particularmente en lo que respecta al suministro efectivo del bien con un nivel de limpieza dentro de límites permisibles, es decir, de 18/16/13 de acuerdo con la norma ISO 4406.

\subsection{Hipótesis específicas}

Habiéndose detectado vínculos principales respecto de ciertos temas en la investigación cualitativa, y teniendo en cuenta los niveles de frecuencia y criticidad de ciertos incidentes, se proponen tres hipótesis relacionadas con las preguntas específicas de investigación expuestas:

- $\quad \mathrm{H}_{1}$ : La ejecución de la programación del suministro de combustible presenta no conformidades en vista de que no se cuenta con una adecuada gestión de proyectos bajo el enfoque del PMI.

- $\quad \mathrm{H}_{2}$ : Los incumplimientos en el equipamiento de camiones cisterna y la continua incursión en fallas operacionales, se evitarían mediante la aplicación de buenas prácticas para la gestión de contratos.

- $\mathrm{H}_{3}$ : La continua incursión en fallas operacionales se evitaría mediante el empoderamiento de la gestión de la cadena de suministro en sus distintos procesos.

\subsection{Variable}

La variable de investigación a considerar es el tipo de sistema de gestión del contrato CB02912; el sistema de gestión de contrato puede ser original o modificado (integral).

\subsubsection{Sistema de gestión modificado (integral) del contrato CB02912}

Es un sistema de gestión de proyectos, es decir, la suma de los procesos, entre otros, necesarios para gestionar un proyecto (PMI, 2013). Se propone medir esta variable por medio de indicadores de desempeño tales como cumplimiento en la atención de órdenes de compra, índices relativos a la seguridad y salud ocupacional (DS 0552010EM, 2010), cantidad de materiales peligrosos utilizados (OIN, 1999), cumplimiento de programas propuestos en el contrato, nivel de satisfacción de los interesados.

\subsubsection{Sistema de gestión original del contrato CB02912}

No existe una gestión definida propiamente para la atención del contrato; sin embargo, la organización trabaja haciendo uso de un sistema integrado de gestión en materia de 
gestión de la calidad, ambiente, seguridad y salud en el trabajo (Petroperú, 2016). Esta variable se mide mediante los indicadores clave de desempeño KPI propuestos en el contrato CB02912 (Azálgara, 2018).

\subsection{Operacionalización de las variables}

La tabla 1 presenta una matriz que sintetiza lo expuesto.

Tabla 1. Matriz de operacionalización de variables

\begin{tabular}{|c|c|c|c|c|}
\hline Hipótesis & Variable & $\begin{array}{c}\text { Definición } \\
\text { conceptual } \\
\text { simplificada }\end{array}$ & $\begin{array}{l}\text { Definición } \\
\text { operacional }\end{array}$ & Indicadores \\
\hline \multirow{3}{*}{$\begin{array}{l}\text { Hi: La reducción de } \\
\text { no conformidades } \\
\text { en el suministro de } \\
\text { combustible diésel B5 } \\
\text { en el proyecto minero } \\
\text { Las Bambas a partir } \\
\text { de la implementación } \\
\text { de estándares de } \\
\text { gestión de proyectos, } \\
\text { calidad, ambiente y } \\
\text { seguridad industrial } \\
\text { en la gestión del } \\
\text { contrato CB02912, } \\
\text { logrando una mejora } \\
\text { de procesos en el } \\
\text { modelo de negocio, } \\
\text { particularmente en } \\
\text { lo que respecta al } \\
\text { suministro efectivo } \\
\text { del bien con un nivel } \\
\text { de limpieza dentro de } \\
\text { límites permisibles. }\end{array}$} & $\begin{array}{l}\text { Sistema } \\
\text { de gestión } \\
\text { original del } \\
\text { contrato } \\
\text { CB02912 }\end{array}$ & $\begin{array}{l}\text { Sistema de gestión } \\
\text { original del contrato } \\
\text { CB02912. }\end{array}$ & $\begin{array}{l}\text { Revisión de } \\
\text { indicadores KPI } \\
\text { del contrato. }\end{array}$ & $\begin{array}{l}\text { Cumplimiento de la } \\
\text { entrega. } \\
\text { Cantidad de devoluciones. } \\
\text { Cantidades de stockout. } \\
\text { Número de incidentes. } \\
\text { Número de incidentes } \\
\text { ambientales. } \\
\text { Cumplimiento de hoja de } \\
\text { ruta. } \\
\text { Cumplimiento } \\
\text { de programas } \\
\text { (responsabilidad social y } \\
\text { asistencia técnica). }\end{array}$ \\
\hline & $\begin{array}{l}\text { Sistema } \\
\text { de gestión } \\
\text { integral del } \\
\text { contrato } \\
\text { CB02912 }\end{array}$ & $\begin{array}{l}\text { Sistema propuesto } \\
\text { de gestión del } \\
\text { contrato CB02912, } \\
\text { basado en la } \\
\text { implementación } \\
\text { de la metodología } \\
\text { del PMI para } \\
\text { la dirección de } \\
\text { proyectos junto } \\
\text { con las normas ISO } \\
\text { 9000, ISO } 14000 \text { y } \\
\text { OHSAS } 18000 .\end{array}$ & $\begin{array}{l}\text { Revisión de } \\
\text { indicadores KPI } \\
\text { del contrato. }\end{array}$ & $\begin{array}{l}\text { Cumplimiento de la } \\
\text { entrega. } \\
\text { Cantidad de devoluciones. } \\
\text { Cantidades de stockout. } \\
\text { Número de incidentes. } \\
\text { Número de incidentes } \\
\text { ambientales. } \\
\text { Cumplimiento de hoja de } \\
\text { ruta. } \\
\text { Cumplimiento } \\
\text { de programas } \\
\text { (responsabilidad social y } \\
\text { asistencia técnica). }\end{array}$ \\
\hline & & & $\begin{array}{l}\text { Revisión de } \\
\text { indicadores } \\
\text { KPI de análisis } \\
\text { comparativo. }\end{array}$ & $\begin{array}{l}\text { Porcentaje incremental de } \\
\text { indicadores de ingeniería } \\
\text { (productividad, utilización, } \\
\text { rendimiento) respecto del } \\
\text { sistema original. }\end{array}$ \\
\hline
\end{tabular}

Elaboración propia 


\subsection{Método y diseño}

Con la finalidad de estudiar casos de incidentes de mediano y bajo potencial acontecidos entre los años 2012 y 2013 en el área de influencia del proyecto minero Las Bambas, relativos a la operación industrial de suministro de combustible diésel B5, se aplica un proceso de investigación conocido como DEXPLOS, que corresponde a un diseño exploratorio secuencial bajo modalidad derivativa (Hernández, Fernández y Baptista, 2010). El diseño de investigación requiere de la aplicación de un enfoque mixto, compuesto por un componente cualitativo y otro cuantitativo. La investigación se realiza en tres fases (figura 2).
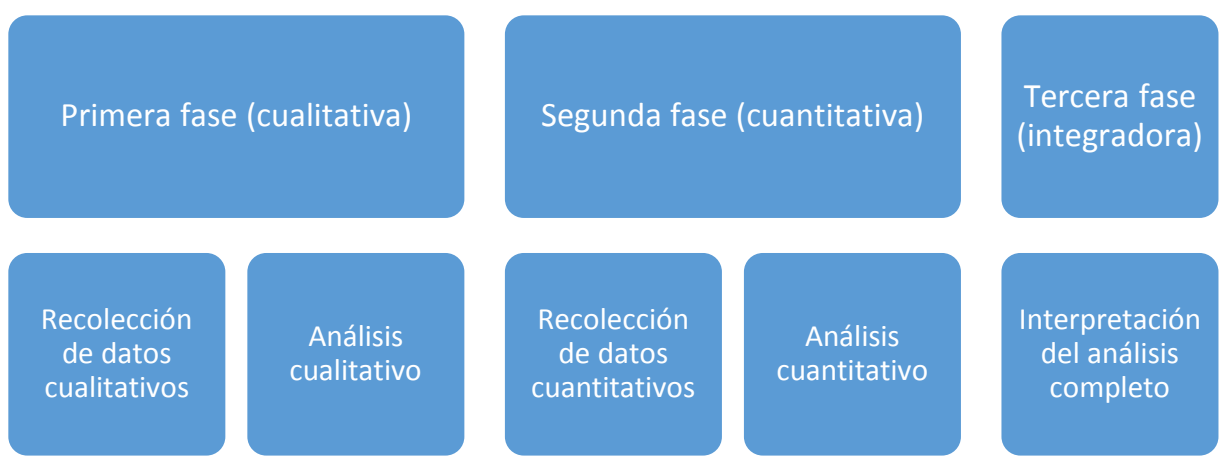

Figura 2. Esquema del diseño exploratorio secuencial

Elaboración propia

\subsubsection{Muestreo}

En la fase cualitativa de la investigación, la población son los incidentes de bajo y mediano potencial acontecidos durante el 2012 y el 2013 en la zona de influencia del proyecto minero Las Bambas. Se trata de unidades de análisis compuestas por incidentes que tuvieron lugar, por un lado, en el marco de la ejecución del contrato de suministro de combustible diésel B5 y, por otro lado, que refieren a la interrupción del suministro regular del bien. La muestra inicial comprende 274 casos procedentes del registro personal del autor de la presente investigación. La muestra es probabilística y de carácter teórico o conceptual.

En la fase cuantitativa, la población son incidentes que evidencian o contribuyen al desabasto de combustible e incumplimiento del nivel de limpieza durante la ejecución efectiva del contrato CB02912. Adicionalmente se tienen unidades de análisis compuestas por incidentes relativos a la ejecución del contrato CB02912 que han sido abordadas en la fase cualitativa. Se genera una muestra de tipo no probabilístico seleccionándose los 
casos en base a la variable severidad del incidente; la severidad se traduce en pérdidas económicas para el proyecto minero.

\subsubsection{Recolección y análisis de datos}

En la fase cualitativa los instrumentos de recolección son, por un lado, archivos personales (registros privados de reportes no oficiales) y por otro lado, artefactos y construcciones grupales o comunitarios. El proceso de recolección y análisis de datos cualitativos se aprecia en la figura 3.

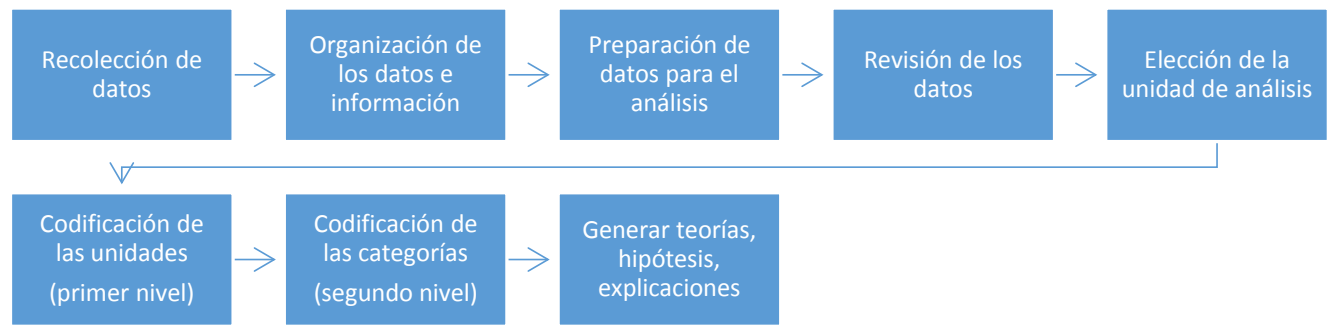

Figura 3. Proceso de análisis y recolección de datos cualitativos

Elaboración propia

En la fase cuantitativa se aplica un análisis de contenido cuantitativo como instrumento de recolección de datos. Posteriormente, en la fase integradora de la investigación se realiza análisis con base en un modelado y una simulación del suministro de combustible (figura 4).

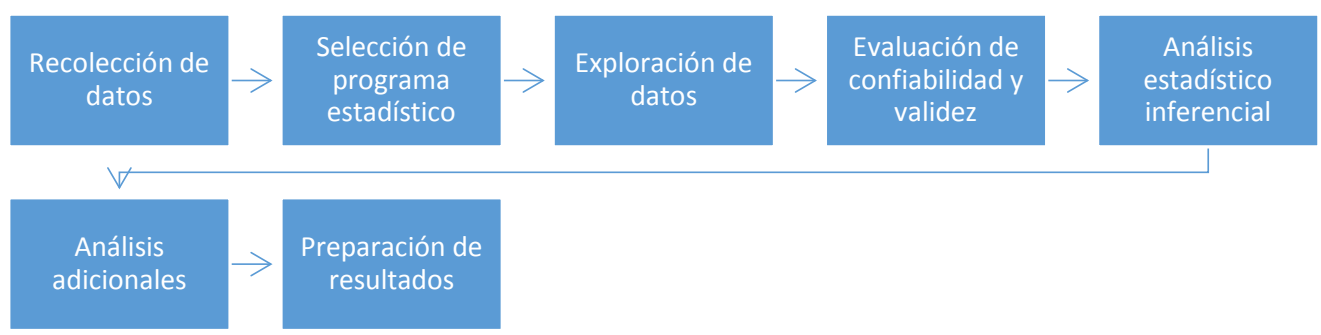

Figura 4. Proceso de análisis y recolección de datos cuantitativos

Elaboración propia 


\subsubsection{Limitaciones}

La presente investigación está limitada en cuanto al uso de fuentes primarias de información, como son los documentos sobre los incidentes (no oficiales), y porque existen limitantes del operador logístico en cuanto a la confidencialidad de la información. Por otro lado, la recolección de datos fue realizada a partir de evidencias generadas mayormente por el operador logístico.

\subsubsection{Visualización gráfica del estudio}

La presente investigación es del tipo DEXPLOS en modalidad comparativa y su esquema es representado en la figura 5 .
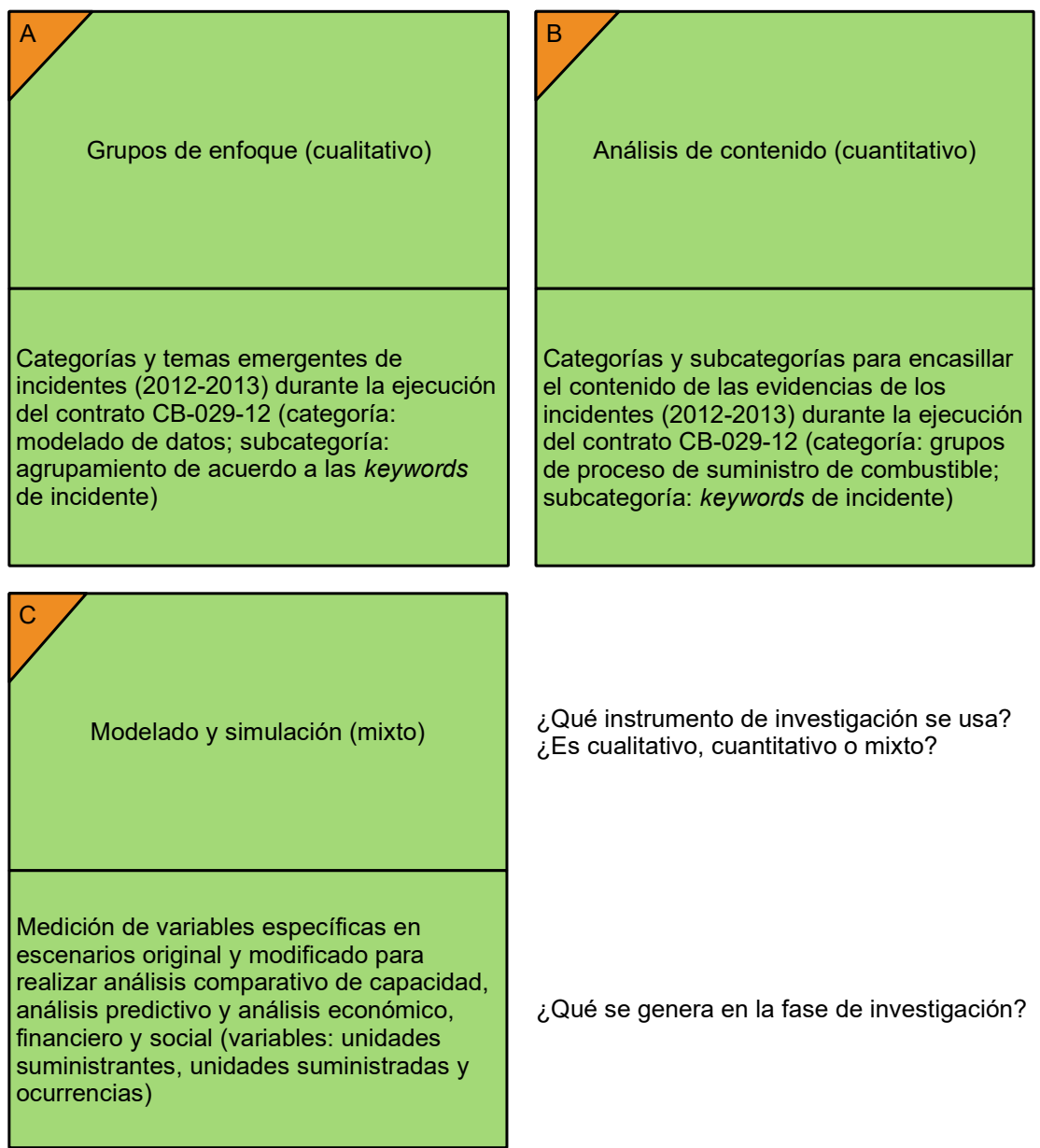

¿Qué instrumento de investigación se usa? ¿Es cualitativo, cuantitativo o mixto?

¿Qué se genera en la fase de investigación?

Figura 5. Visualización gráfica de la investigación tipo DEXPLOS

Elaboración propia 


\section{RESULTADOS}

\subsection{Investigación en fases cualitativa y cuantitativa}

Con la finalidad de focalizar el presente artículo en el objeto de la investigación, no se presentan a detalle los resultados de las fases cualitativa y cuantitativa. La relación secuencial entre las fases implica del mismo modo un desarrollo evolutivo que inicia en lo cualitativo para continuar con lo cuantitativo, para así finalizar con lo integrador.

En la investigación en fase cualitativa se detectaron, como incidentes más frecuentes, incumplimientos de programación, no conformidades en el equipamiento de camiones cisterna y fallas mecánicas; lo anterior correspondería mayormente a incidentes de mediano y bajo potencial. De acuerdo con los incidentes acontecidos se detectan como oportunidades de mejora más frecuentes al abordar la gestión de la cadena de suministro, la gestión de contratos o, en su defecto, la implementación de buenas prácticas para la gestión de proyectos.

En la fase cuantitativa se detectan las siguientes oportunidades de mejora que contribuirían más representativamente a la reducción y prevención de incidentes:

1. Aplicación de buenas prácticas para la dirección de proyectos bajo el enfoque del PMI (85,04 \% de las veces).

2. Aplicación de la gestión de cambio (66,42 \% de las veces).

3. Aplicación de gestión organizacional de proyecto (64,96 \% de las veces).

El primer aspecto señala la aplicación de un enfoque basado en procesos (OIN, 2008). Los dos subsiguientes apuntan hacia un enfoque de competencias bajo los lineamientos del PMI (2007). Teniendo en consideración únicamente la aplicación de buenas prácticas para la dirección de proyectos bajo el enfoque del PMI, se concluye que las fallas operacionales son el tipo de incidente sujeto a mayor reducción y prevención $(53,28 \%$ de las veces), lo cual coincide con lo que resulta primordial atender para una ejecución efectiva del contrato CB02912. Lo anterior se traduce en la reducción y prevención de los derroches principales: tiempo (70,44 \% de las veces) y equipos ( $46,35 \%$ de las veces).

Es viable generalizar el comportamiento de las ocurrencias acontecidas durante la ejecución de contrato CB02912 a partir de los 274 casos reunidos para la presente investigación. Sin embargo, la correspondencia con la realidad práctica se verifica tan solo similar y correspondiente para los años 2012 y 2013, en niveles regular y alto respectivamente; posteriormente, los niveles de similitud y correspondencia son bajos. La fecha del incidente se explica particularmente mediante el tipo de incidente a un nivel estadístico (ANOVA one-way) en un 28,78 \%. La relación anterior se expresa mediante la ecuación:

$$
y=0,04193+0,008421 x-0,000010 x^{2}
$$

Donde $y$ es la fecha del incidente y $x$ el tipo de incidente. 


\subsection{Investigación en fase integradora}

Los resultados obtenidos en la investigación en su fase integradora se aprecian en la tabla 2.

Tabla 2

Resultados de investigación en fase integradora

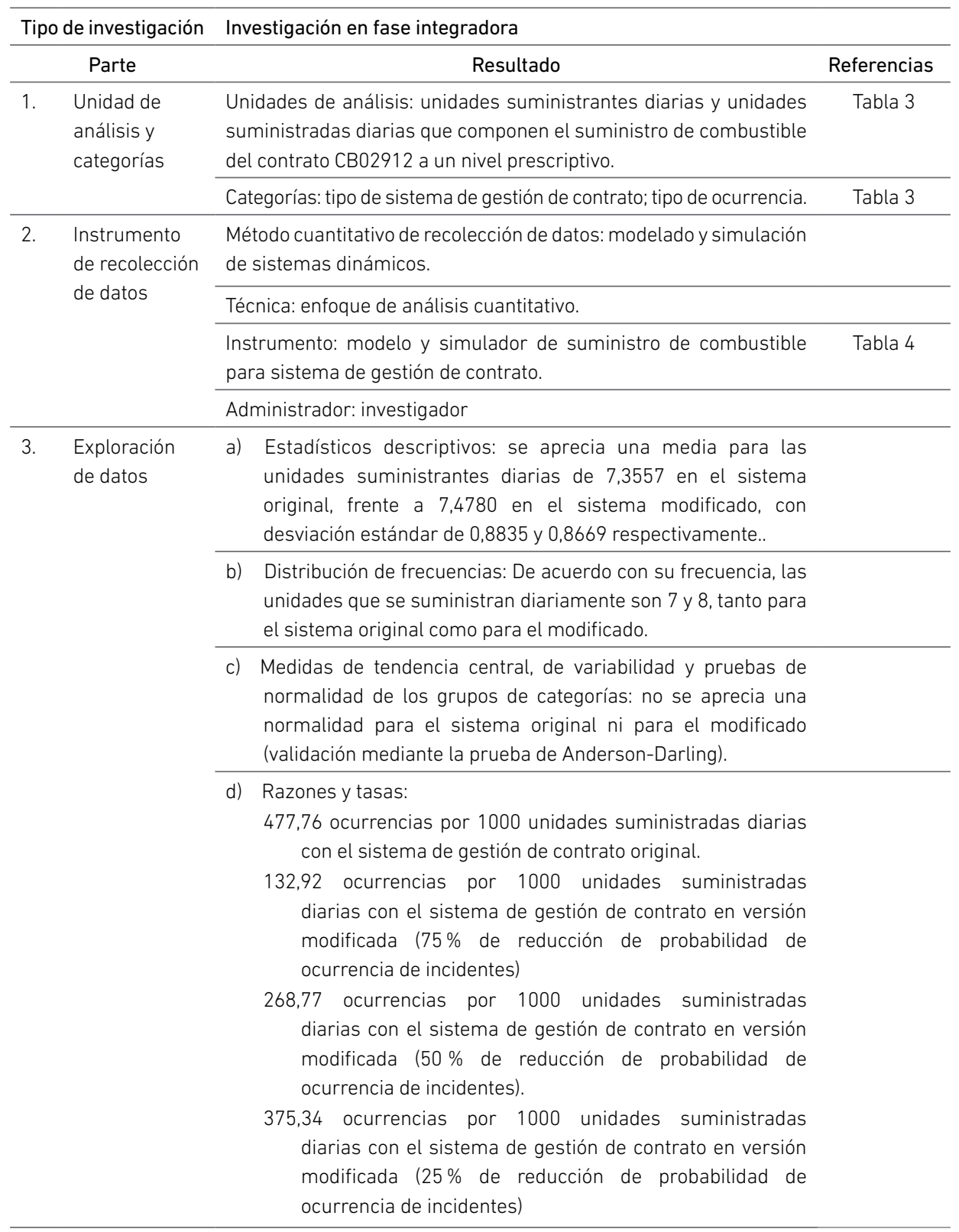


(continuación)

\begin{tabular}{|c|c|c|c|c|}
\hline & & & $\begin{array}{l}\text { 375,34 ocurrencias por } 1000 \text { unidades suministradas diarias con } \\
\text { el sistema de gestión de contrato en versión modificada ( } 25 \% \\
\text { de reducción de probabilidad de ocurrencia de incidentes) }\end{array}$ & \\
\hline \multirow[t]{14}{*}{4.} & \multirow{14}{*}{$\begin{array}{l}\text { Confiabilidad, } \\
\text { validez y } \\
\text { objetividad }\end{array}$} & Cor & fiabilidad & \\
\hline & & & Método para determinar la confiabilidad: formas alternas & \\
\hline & & & Número de análisis de elementos: 1. & \\
\hline & & & Correlación de Pearson: 0,918 & \\
\hline & & & Alfa de Cronbach: 0,9571 & \\
\hline & & Niv & el de similitud: fiabilidad alta & \\
\hline & & & Nivel de consistencia interna: fiabilidad alta & \\
\hline & & & Validez & \\
\hline & & & $\begin{array}{l}\text { a) Obtención (validez de contenido + validez de criterio + validez } \\
\text { de constructo): } 3\end{array}$ & \\
\hline & & & b) Validez global del instrumento: 0,9583 & \\
\hline & & Obj & etividad & \\
\hline & & & Objetividad & \\
\hline & & & a) Permeabilidad (limitación: 1 único investigador) & \\
\hline & & & $\begin{array}{l}\text { b) Estandarización (utilización de modelo con componentes } \\
\text { aceptados en el sector de energía y minas) }\end{array}$ & \\
\hline \multirow[t]{15}{*}{5.} & \multirow{15}{*}{$\begin{array}{l}\text { Análisis } \\
\text { comparativo } \\
\text { de capacidad }\end{array}$} & a) & Análisis comparativo de capacidad 1 & Tabla 5 \\
\hline & & & Proceso de línea base: variables del sistema original & \\
\hline & & & Proceso mejorado: variables del sistema modificado & \\
\hline & & & $\begin{array}{l}\text { Resultado: la probabilidad de producir una unidad sin defecto } \\
\text { mejoró de } 62,0 \text { a } 87,6 \%\end{array}$ & \\
\hline & & & Contexto: reducción de $75 \%$ de incidentes & \\
\hline & & b) & Análisis comparativo de capacidad 2 & Tabla 5 \\
\hline & & & Proceso de línea base: variables del sistema original & \\
\hline & & & Proceso mejorado: variables del sistema modificado & \\
\hline & & & $\begin{array}{l}\text { Resultado: la probabilidad de producir una unidad sin defecto } \\
\text { mejoró de } 62,0 \text { a } 76,4 \%\end{array}$ & \\
\hline & & & Contexto: reducción de $50 \%$ de incidentes & \\
\hline & & c) & Análisis comparativo de capacidad 3 & Tabla 5 \\
\hline & & & Proceso de línea base: variables del sistema original & \\
\hline & & & Proceso mejorado: variables del sistema modificado & \\
\hline & & & $\begin{array}{l}\text { Resultado: la probabilidad de producir una unidad sin defecto } \\
\text { mejoró de } 62,0 \text { a } 68,7 \%\end{array}$ & \\
\hline & & & Contexto: reducción de $25 \%$ de incidentes & \\
\hline \multirow[t]{5}{*}{6.} & \multirow{5}{*}{$\begin{array}{l}\text { Análisis } \\
\text { predictivo }\end{array}$} & Pro & pósito: escoger modelos predictivos que expliquen los datos & \\
\hline & & $\begin{array}{l}\text { Pro } \\
\text { dat }\end{array}$ & $\begin{array}{l}\text { blema: se requiere detectar patrones de comportamiento de los } \\
\text { os }\end{array}$ & \\
\hline & & Aná & lisis predictivo 1: aprendizaje automático & \\
\hline & & & $\begin{array}{l}\text { a1) Aprendizaje automático sin supervisión. Escenario: sistema } \\
\text { original }\end{array}$ & \\
\hline & & & Algoritmo K-Means: 5 centroides & \\
\hline
\end{tabular}


Evaluación: se aprecia una tendencia respecto de las ocurrencias para con las operaciones que incluyen 7 unidades suministradas diarias (base $=$ probabilidad de ocurrencia)

A2) Aprendizaje automático sin supervisión. Escenario: sistema modificado

Algoritmo K-Means: 5 centroides

Evaluación: se aprecia una tendencia respecto de las ocurrencias para con las operaciones que incluyen 7 u 8 unidades suministradas diarias (base $=$ probabilidad de ocurrencia)

b1) Aprendizaje automático con supervisión. Escenario: sistema original

Modelo predictivo más adecuado: bosque al azar (random forest) / k-vecino más cercano (k-nearest neighbour)

b2) Aprendizaje automático con supervisión. Escenario: sistema modificado

Modelo predictivo más adecuado: k-vecino más cercano

Análisis predictivo 2: modelado dinámico de series temporales

a)] Sistema original

Modelo: modelo autorregresivo integrado de promedio móvil (ARIMA)

Especificación: ARIMA $(2,1,1) \times(1,1,1)$

b) Sistema modificado

Modelo: modelo autorregresivo integrado de promedio móvil (ARIMA)

Especificación: ARIMA $(2,1,1) \times(1,1,1)$

7. Análisis Propósito: evidenciar la mejor condición económica del sistema económico, modificado frente al sistema original y generar un valor referencial financiero correspondiente al incremento.

y social Metodología: análisis comparativo u horizontal

Recolección de datos: se recolectan y se generan datos Tabla 6 prescriptivos relativos a las ventas industriales

Procesamiento de la datos y análisis de resultados:

Figura 6

a) Resultados desde una perspectiva de giro de negocio Ingreso potencial por incremento en ventas industriales en PEN 17429168 (incremento en ventas industriales de 1,6459\%)

b) Resultados desde una perspectiva tributaria Ingreso tributario potencial por incremento en ventas industriales en PEN: 5207373 (incremento en recaudación tributaria de 1,6332\%)

Evaluación:

Se evidencia cierto nivel de correspondencia con la realidad práctica

Se evidencia la mejor condición económica de la solución modificada en comparación con la solución original

\section{Elaboración propia}




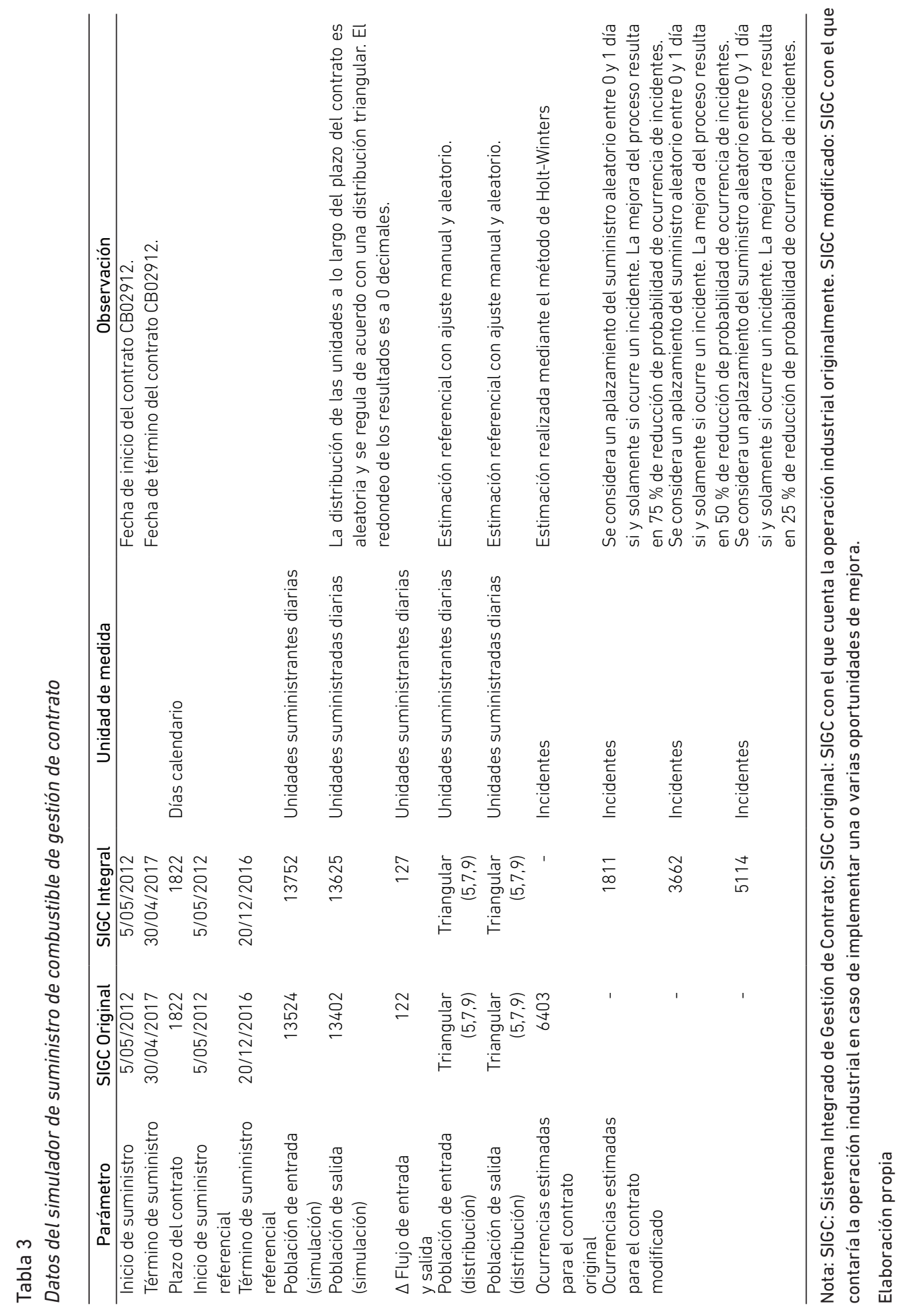




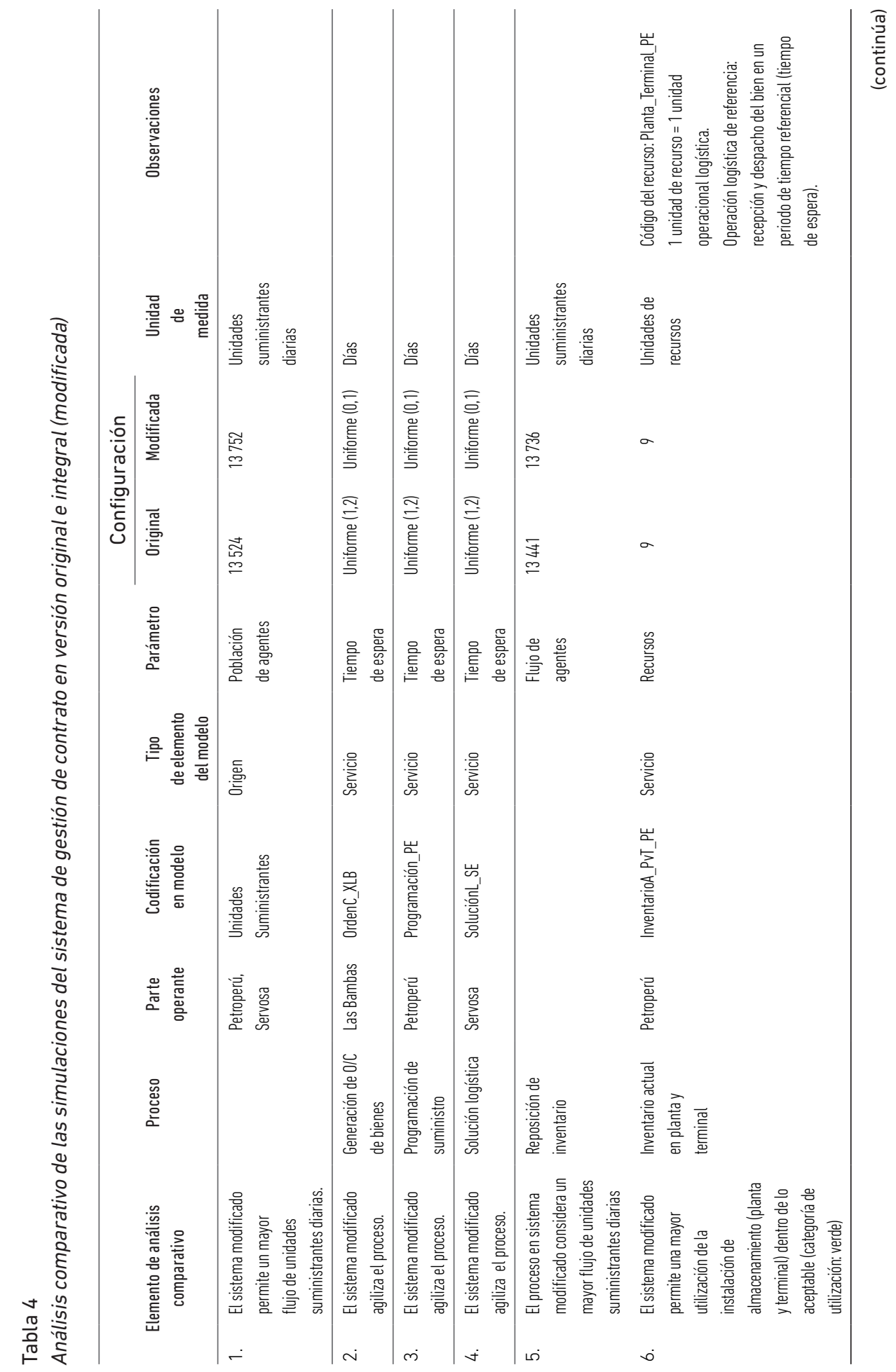




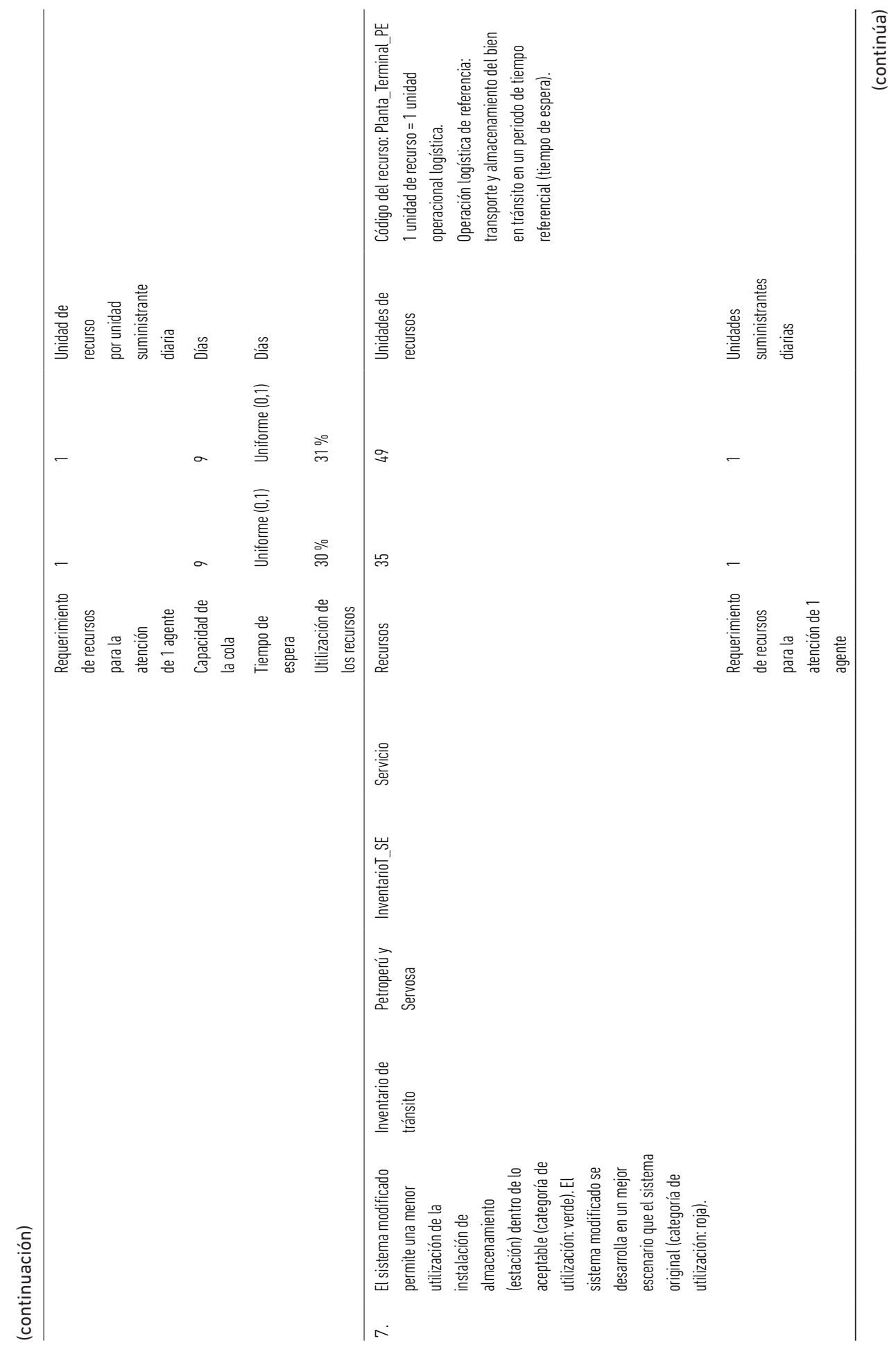




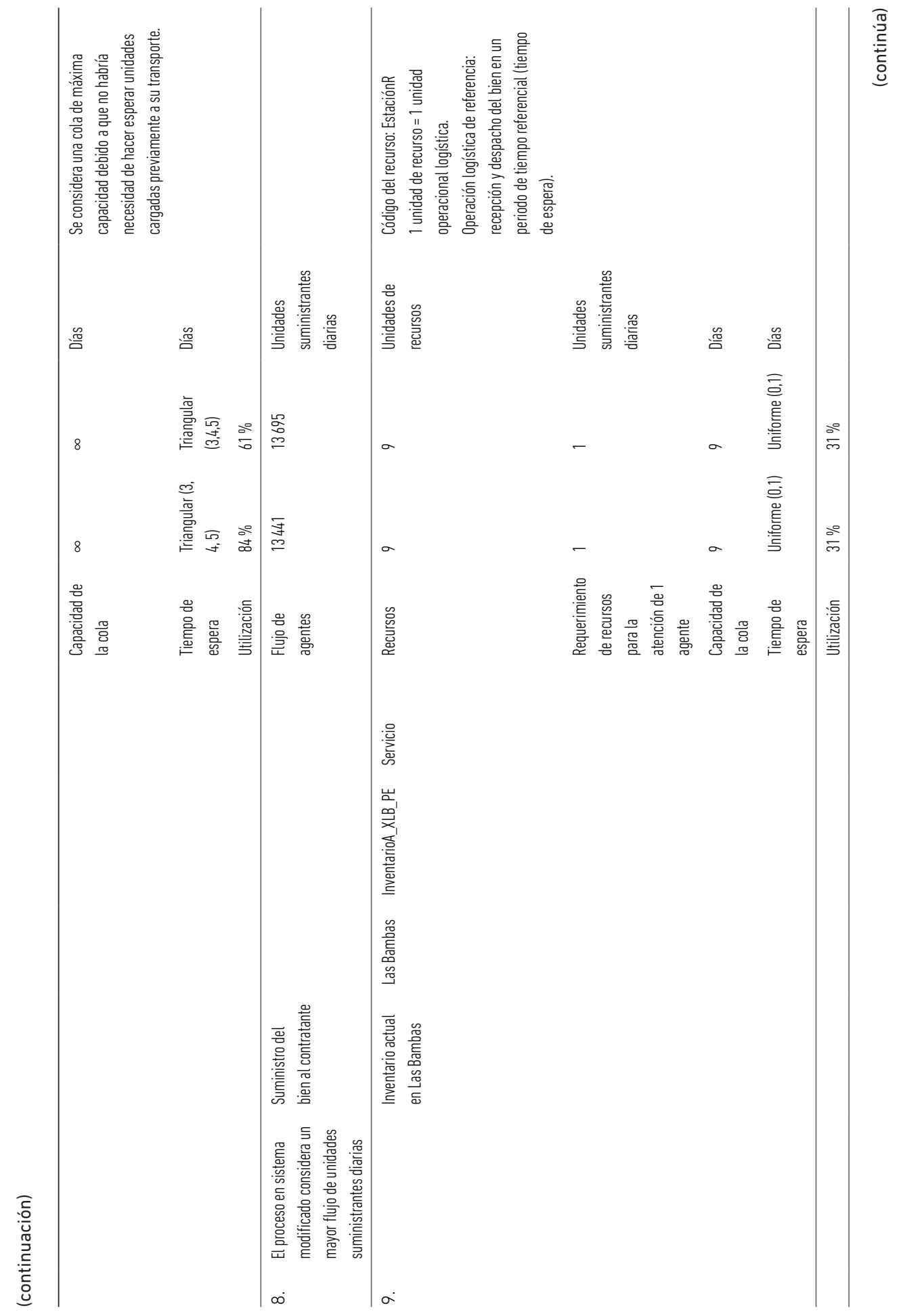


Análisis de una operación industrial de suministro de combustible diésel B5

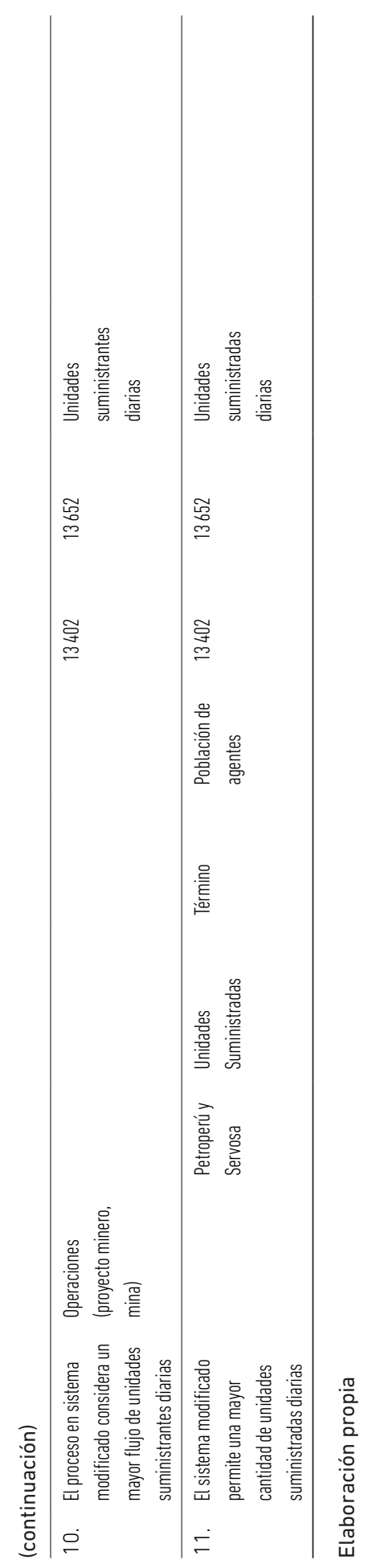


Tabla 5

Resultados del análisis comparativo de capacidad

\begin{tabular}{|c|c|c|c|c|c|c|c|}
\hline $\begin{array}{c}\text { Análisis } \\
\text { comparativo }\end{array}$ & Procesos & $\begin{array}{l}\text { Tipo de } \\
\text { proceso }\end{array}$ & Variable & $\begin{array}{l}\text { Tipo de } \\
\text { variable }\end{array}$ & $\begin{array}{l}\text { Descripción } \\
\text { de variable }\end{array}$ & Mejora & $\begin{array}{c}\% \text { de } \\
\text { reducción } \\
\text { de incidentes }\end{array}$ \\
\hline \multirow[t]{4}{*}{1.} & \multirow[t]{2}{*}{1.} & \multirow[b]{2}{*}{ Línea base } & Producto & $\begin{array}{l}\text { Suministro de } \\
\text { combustible }\end{array}$ & $\begin{array}{l}\text { Unidades suministradas } \\
\text { en sistema de gestión de } \\
\text { contrato original. }\end{array}$ & \multirow{4}{*}{$\begin{array}{l}\text { La probabilidad de } \\
\text { producir una unidad sin } \\
\text { defecto mejoró } \\
\text { de } 62,0 \text { a } 87,6 \% \text {. }\end{array}$} & № aplica \\
\hline & & & Defecto & $\begin{array}{l}\text { Incidente } \\
\text { operacional }\end{array}$ & $\begin{array}{l}\text { Pronósticos de incidentes } \\
\text { obtenidos en base a método } \\
\text { de Holt-Winters con un } \\
\text { modelo aditivo generado } \\
\text { con datos reales. }\end{array}$ & & \\
\hline & \multirow[t]{2}{*}{2.} & \multirow{2}{*}{ Mejorado } & Producto & $\begin{array}{l}\text { Suministro de } \\
\text { combustible }\end{array}$ & $\begin{array}{l}\text { Unidades suministradas } \\
\text { en sistema de gestión de } \\
\text { contrato modificado. }\end{array}$ & & $75 \%$ \\
\hline & & & Defecto & $\begin{array}{l}\text { Incidente } \\
\text { operacional }\end{array}$ & $\begin{array}{l}\text { Datos que derivan de } \\
\text { aquellos correspondientes } \\
\text { a la variable ocurrencias. }\end{array}$ & & \\
\hline \multirow[t]{5}{*}{2.} & \multirow[t]{3}{*}{1.} & \multirow{3}{*}{ Línea base } & Producto & $\begin{array}{l}\text { Suministro de } \\
\text { combustible }\end{array}$ & $\begin{array}{l}\text { Unidades suministradas } \\
\text { en sistema de gestión de } \\
\text { contrato original. }\end{array}$ & \multirow{5}{*}{$\begin{array}{l}\text { La probabilidad de } \\
\text { producir una unidad sin } \\
\text { defecto mejoró } \\
\text { de } 62,0 \text { a } 76,4 \% \text {. }\end{array}$} & No aplica \\
\hline & & & Defecto & $\begin{array}{l}\text { Incidente } \\
\text { operacional }\end{array}$ & $\begin{array}{l}\text { Pronósticos de incidentes } \\
\text { obtenidos en base a método }\end{array}$ & & \\
\hline & & & & & $\begin{array}{l}\text { de Holt-Winters con un } \\
\text { modelo aditivo generado } \\
\text { con datos reales. }\end{array}$ & & \\
\hline & \multirow[t]{2}{*}{2.} & \multirow{2}{*}{ Mejorado } & Producto & $\begin{array}{l}\text { Suministro de } \\
\text { combustible }\end{array}$ & $\begin{array}{l}\text { Unidades suministradas } \\
\text { en sistema de gestión de } \\
\text { contrato modificado. }\end{array}$ & & $50 \%$ \\
\hline & & & Defecto & $\begin{array}{l}\text { Incidente } \\
\text { operacional }\end{array}$ & $\begin{array}{l}\text { Datos que deriva de aquellos } \\
\text { correspondientes a la } \\
\text { variable ocurrencias. }\end{array}$ & & \\
\hline \multirow[t]{4}{*}{3.} & \multirow[t]{2}{*}{1.} & \multirow[b]{2}{*}{ Línea base } & Producto & $\begin{array}{l}\text { Suministro de } \\
\text { combustible }\end{array}$ & $\begin{array}{l}\text { Unidades suministradas } \\
\text { en sistema de gestión de } \\
\text { contrato original. }\end{array}$ & \multirow{4}{*}{$\begin{array}{l}\text { La probabilidad de } \\
\text { producir una unidad sin } \\
\text { defecto mejoró de } 62,0 \\
\text { a } 68,7 \% \text {. }\end{array}$} & No aplica \\
\hline & & & Defecto & $\begin{array}{l}\text { Incidente } \\
\text { operacional }\end{array}$ & $\begin{array}{l}\text { Pronósticos de incidentes } \\
\text { obtenidos en base a método } \\
\text { de Holt-Winters con un } \\
\text { modelo aditivo generado } \\
\text { con datos reales. }\end{array}$ & & \\
\hline & \multirow[t]{2}{*}{2.} & \multirow[t]{2}{*}{ Mejorado } & Producto & $\begin{array}{l}\text { Suministro de } \\
\text { combustible }\end{array}$ & $\begin{array}{l}\text { Unidades suministradas } \\
\text { en sistema de gestión de } \\
\text { contrato modificado (véase } \\
\text { el apéndice M) }\end{array}$ & & $25 \%$ \\
\hline & & & Defecto & $\begin{array}{l}\text { Incidente } \\
\text { operacional }\end{array}$ & $\begin{array}{l}\text { Datos que derivan de } \\
\text { aquellos correspondientes } \\
\text { a la variable Ocurrencias. }\end{array}$ & & \\
\hline
\end{tabular}

\section{Elaboración propia}


Tabla 6

Datos recolectados para el análisis económico, financiero y social

\begin{tabular}{|c|c|c|c|}
\hline Datos & Tipo de datos & $\begin{array}{c}\text { Tipo de } \\
\text { elemento } \\
\text { de proceso }\end{array}$ & Fuente de información \\
\hline Unidades suministradas diarias & Prescriptiva & Entrada & \multirow{4}{*}{$\begin{array}{l}\text { La presente investigación } \\
\text { en fase integradora }\end{array}$} \\
\hline Ventas industriales & Prescriptiva & Entrada & \\
\hline Impuesto General a las Ventas (IGV) & Prescriptiva & Entrada & \\
\hline Impuesto Selectivo al Consumo (ISC) & Prescriptiva & Entrada & \\
\hline Precio unitario & Real & Entrada & \multirow{2}{*}{ Contrato CB02912 } \\
\hline Flete & Real & Entrada & \\
\hline Tasa de interés pasiva PEN (TIPMN) & Real & Entrada & \multirow{2}{*}{$\begin{array}{l}\text { Superintendencia de Banca } \\
\text { y Seguros del Perú }\end{array}$} \\
\hline Tipo de cambio (compra y venta) & Real & Entrada & \\
\hline $\begin{array}{l}\text { Tasas de rendimiento de bonos de } \\
\text { Estados Unidos ( } 10 \text { años) }\end{array}$ & Real & Entrada & investing.com \\
\hline Flujos de efectivo actualizados & Prescriptiva & Salida & \multirow{3}{*}{$\begin{array}{l}\text { Datos generados } \\
\text { en el presente apartado }\end{array}$} \\
\hline $\begin{array}{l}\text { Ingreso potencial por incremento en } \\
\text { ventas industriales }\end{array}$ & Prescriptiva & Salida & \\
\hline $\begin{array}{l}\text { Ingreso tributario potencial por } \\
\text { incremento en ventas industriales }\end{array}$ & Prescriptiva & Salida & \\
\hline
\end{tabular}

Nota: todos los datos recolectados para el plazo de vigencia del contrato CB02912 (5 de marzo del 2012 al 30 de abril del 2017). El flete (y por lo tanto el precio unitario) está sujeto a dos fases: la primera refiere al suministro de combustible desde la planta Cusco y la segunda al suministro desde el terminal Mollendo.

Elaboración propia

\section{Incremento}

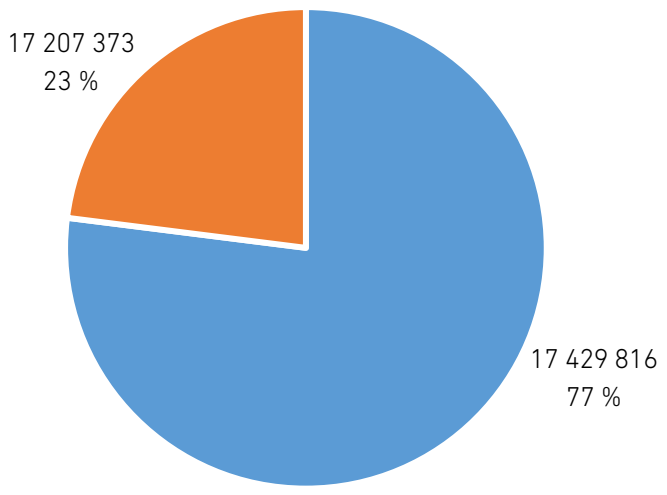

- Giro de negocio $\quad$ Tributario

Figura 6a. Dashboard de consolidación de resultados 
Incremento (\%)

(Base: flujo de efectivo en sistema original)

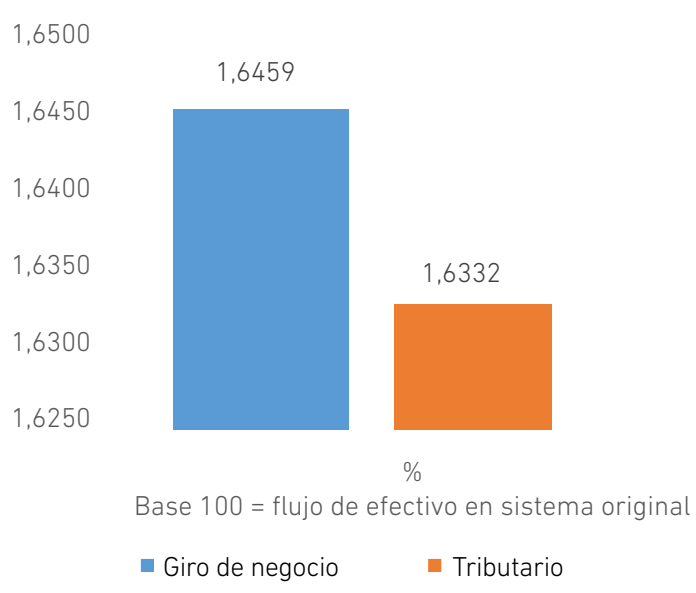

Incremento (\%)

(Participación del sistema modificado)

1,6250

1,6200

1,6192

1,6150

1,6100

1,6050

1,6000

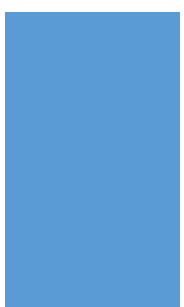

1,6070

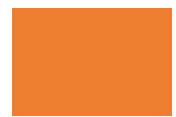

$\%$

Base 100 = flujo de efectivo en solución modificada (integral)

- Giro de negocio $\quad$ - Tributario

Figura 6b. Dashboard de consolidación de resultados

Nota: Se tiene un incremento total de S/ 22636541.

Elaboración propia

\section{CONCLUSIONES Y APUNTES FINALES}

\subsection{Conclusiones}

Se concluye que modificar el sistema de gestión original del contrato CB0912 mediante la implementación de buenas prácticas para la gestión de proyectos bajo el enfoque del PMI, así como, focalizarlo en la operación industrial con el uso de las normas ISO 9000 , ISO 14000 y OHSAS 18000 , contribuye a generar soluciones que optimizan el uso de recursos, maximizando por un lado el ingreso por ventas industriales y por otro lado la recaudación tributaria. Las labores de optimización tienen su sustento en modificaciones del sistema de gestión que van en la línea de los cinco bloques de relaciones propuestos en la presente investigación. El modelo teórico para la mejora del modelo de negocio del contrato CB02912, y el modelo y simulador de Suministro de Combustible para el Sistema de Gestión de Contrato (MOSCOM-SGC) contribuyen a la detección de aspectos a modificar. La modificación del sistema de gestión original genera un nuevo sistema de gestión a partir de una gestión de integración, lo cual deviene en una mejor condición económica, financiera y social.

Respecto a la contrastación de la hipótesis principal, se verifica que la implementación de buenas prácticas bajo el enfoque del PMI, junto con aspectos del sistema original 
relativos a calidad, ambiente y seguridad industrial, contribuye a la generación de un sistema de gestión integral que coloca el nuevo sistema en una mejor condición económica, financiera y social, así como operacional. En este último aspecto, se incrementan las probabilidades de éxito de operar con una unidad suministrada diaria sin defecto; de 68,7 a $87,6 \%$, dependiendo de la meta de prevención y reducción de incidentes. En cuanto a los aspectos económico, financiero y social, se obtiene un incremento en ventas industriales de 1,6459 \% (PEN 17429 168) y en recaudación de impuestos, de 1,6332 \% (PEN 5207 373).

En cuanto a la contrastación de hipótesis específicas se verifica que la falla de programas tendría su origen en una motivación poco adecuada del personal y la utilización de procedimientos de trabajo poco adecuados. Por otro lado, el incumplimiento de estándares tendría su origen en el uso de procedimientos poco adecuados en lo que se refiere a la operación con depósitos y almacenamientos peligrosos. La ocurrencia de fallas operacionales se debería a la utilización insegura de equipos.

\subsection{Apuntes finales}

En el marco de un contrato vinculado a la gran minería del Perú, como es el caso del contrato CB02912, con la finalidad de lograr una operación industrial de suministro de combustible diésel B5 basada en soluciones vinculadas a la optimización de los distintos recursos con que cuenta, además de un monitoreo y control efectivos, se recomienda el uso del modelo teórico para la mejora del modelo de negocio del contrato, y el modelo y simulador de suministro de combustible para el sistema de gestión de contrato (MOSCOM-SGC), ambos instrumentos son útiles en otros contextos similares, como parte del pool de herramientas de mejora continua para labores de seguimiento y control.

La presente investigación pone en evidencia, entre otras cosas, que para que el sistema de gestión original de suministro de combustible diésel B5 devenga en un sistema en mejores condiciones, es necesario aplicar una gestión de la integración entre los lineamientos del PMI y las series de normas ISO 9000, ISO 14000 y OHSAS 18000. El sistema resultante sería un sistema de gestión modificado, también llamado sistema integrado de gestión por contrato. El modelo y simulador MOSCOM-SGC y el modelo teórico propuesto para la mejora del modelo de negocio del contrato CB02912 se constituyen y se proponen como herramientas de mejora continua que contribuyen a los fines del grupo de procesos de seguimiento (o monitoreo) y control.

Consideramos conveniente abordar lo que se conoce como animación, con la finalidad de incrementar la interactividad del modelo y simulador MOSCOM-SGC. Se sugiere mejorar el entorno de simulación incluyendo una interfaz gráfica con objetos 3D, lo cual se llevaría a cabo utilizando la herramienta de simulación AnyLogic u otra similar. Asimismo, recomendamos incluir la perspectiva del modelo de referencia de las 
operaciones de cadena de suministro, ya que en la presente investigación se identifica un grupo de procesos del suministro de combustible para los fines de la cadena. Dicho modelo es conocido y cuenta con aprobación a nivel internacional.

Finalmente se sugiere considerar el modelo de la presente investigación como método no solamente aplicable para fines académicos, como en el caso original, sino también para el campo, es decir, en una operación real. Se sugiere además considerar el lugar de trabajo: una oficina de gestión técnica de contrato donde se cumplan las funciones de seguimiento y control. El lugar apropiado sería la zona de influencia del proyecto minero. Adicionalmente es necesario considerar que no es suficiente que la gestión técnica de contrato cuente con un lugar físico sino también con el soporte tecnológico adecuado en un contexto de portabilidad.

\section{REFERENCIAS}

Agencia de la Promoción de la Inversión Privada (Proinversión) (2005). Las Bambas. Un modelo de desarrollo sostenible. Lima: Proinversión.

Azálgara, M. (2018). Análisis de una Operación Industrial de Suministro de Combustible Diésel B-5 y desarrollo de optimización basada en las metodologías PMI, ISO 9000, ISO 14000, y OHSAS 18000. (Tesis doctoral). México: Universidad Internacional Iberoamericana.

Custodio, P. (8 de julio del 2013). Las idas y venidas de la adquisición de Las Bambas. Semana Económica. Recuperado de http://semanaeconomica.com/article/ sectores-y-empresas/mineria/120033-adquirir-las-bambas-no-es-cosa-facil/

Decreto Supremo 0402014 EM (12 de noviembre del 2014). Decreto legislativo que aprueba el Reglamento de Protección Gestión Ambiental para las Actividades de Explotación, Beneficio, LaborGeneral, Transportey Almacenamiento. Recuperado de https://busquedas.elperuano.pe/download/full/6XIIVNeY4Ub9mix9Pq-nxX

Golder Associates Perú, S. A. (2010). Estudio de impacto ambiental de proyecto minero Las Bambas. Resumen ejecutivo. Lima: Golder Associates Perú. Recuperado de: http://gestion2.e3.pe/doc/0/0/1/1/3/113512.pdf

Hernández, R., Fernández C. y Baptista, P. (2006). Metodología de la investigación. México: McGraw-Hill Interamericana.

Hernández, R., Fernández C. y Baptista, P. (2010). Metodología de la investigación. México: McGraw-Hill Interamericana.

Michelmore, A. (21 de julio del 2014). Accionistas de MMG aprueban adquisición de Las Bambas. Gestión. Recuperado de https://gestion.pe/economia/empresas/ accionistas-mmg-aprueban-adquisicion-bambas-66188 
Ministerio de Energía y Minas (2015). Anuario minero 2014. Lima: Ministerio de Energía y Minas. Recuperado de http://www.minem.gob.pe/_publicacion.php?idSector=1 \&idPublicacion $=501$

Montoya, K. (23 de septiembre del 2015). Proyecto Las Bambas está casi listo: su avance supera el 95\%. Semana Económica. Recuperado de http://semanaeconomica.com/article/sectores-y-empresas/mineria/169950-proyecto -las-bambas-esta-casi-listo-avance-supera-el-95/

Observatorio de Conflictos Mineros (2013). 13º observatorio de conflictos mineros en el Perú. Reporte segundo semestre 2013. Recuperado de http://conflictosmineros.org. pe/2017/11/27/13o-observatorio-de-conflictos-mineros-reporte-segundo-semestre-2013/

Organización Internacional de Normalización (OIN) (noviembre de 1999). Norma ISO 14031:1999(es), Gestión Ambiental. Evaluación del desempeño ambiental. Directrices. Recuperado de https://www.iso.org/contents/data/standard/02/ 31/23149.html

Organización Internacional de Normalización (OIN) (noviembre del 2008). Norma ISO 9001:2008(es), Sistemas de Gestión de la Calidad. Recuperado de https://www. iso.org/obp/ui/\#iso:std:iso:9001:ed-4:v2:es:sec:B

Organismo Supervisor de la Inversión de Energía y Minería (Osinergmin) (2015). La industria de los hidrocarburos líquidos en el Perú: 20 años de aporte al desarrollo del país. Lima.

Petróleos del Perú, S. A. (Petroperú) (2011). Especificaciones técnicas de combustible diésel B5 S50. Recuperado de https://www.petroperu.com.pe/productos/ combustibles/diesel-ultra/

Petróleos del Perú, S. A. (Petroperú) (2016). Petroperú comprometido con el cuidado del ambiente. Recuperado de https://1drv.ms/b/s!Ar876AhKJSKRgtUV g04zgdbxbyalfA

Project Management Institute (PMI) (2007). Project Manager Competency Development (PMCD) Framework. Pensilvania: PMI.

Project Management Institute (PMI) (2013). Guía de los fundamentos para la dirección de proyectos (Guía del PMBOK). Pensilvania: PMI.

Render, B., Stair, R. y Hanna, M. (2012). Métodos cuantitativos para los negocios. México: Pearson Educación.

Samardzich, C. (13 de abril del 2014). Venta de Las Bambas: El deal más grande de la historia del Perú. Semana Económica. Recuperado de http://semanaeconomica. 
com/article/extractivos/134243-las-bambas-venta-glencore-xstrata-mmgchina-minmetals-el-deal-mas-grande-de-la-historia-del-peru/

Waters, D. (2010). Global Logistics. Filadelfia: Kogan Page Limited.

Xstrata Copper (2013). Informe de sostenibilidad 2012. Recuperado de https://www. unglobalcompact.org/system/attachments/23113/original/Informe_de_ Sostenibilidad_2012.pdf?1372891868 